\title{
Risk Factors for Differentiated Thyroid Cancer. A Case- Control Study in Cuban Population
}

Celia M Pereda ${ }^{1 *}$, J uan J Lence-Anta ${ }^{1}$, Rosa María Ortíz ${ }^{1}$, Silvia Turcios ${ }^{4}$, Fabienne Lesueur ${ }^{2,3}$, Constance Xhaard ${ }^{6-8}$, Yan Ren ${ }^{6-8}$, Milagros Velasco $^{1}$, Mae Chappe ${ }^{1}$, Idalmis Infante ${ }^{1}$, Marlene Bustillo $^{1}$, Anabel García1, Enora Clero ${ }^{6-8}$, Stéphane Maillard $^{6-8}$, Francesca Damiola ${ }^{9}$, Carole Rubino ${ }^{6-8}$, Sirced Salazar', Haoiinda Kassim ${ }^{6,7}$, Maroulio Pertesi $^{3}$, Nivonirina Robinot ${ }^{3}$, Axelle Leufroy ${ }^{10}$, Thierry Guérin ${ }^{10}$, Laurent Noel ${ }^{11}$, Rodrigue S.Allodji ${ }^{6-8}$, Regla Rodriguez ${ }^{5}$, and Florent de Vathaire $^{6-8}$

'Institute of Oncology and Radiobiology, Cuba

2The French National Institute of Health and Medical Research (Inserm), Institut Curie, France

${ }^{3}$ Genetic Cancer Susceptibility, International Agency for Research on Cancer (IARC), France

${ }^{4}$ National Institute of Endocrinology, Cuba

${ }^{5}$ Department of Foreign Affairs, Public Health Ministry, Cuba

${ }^{6}$ The French National Institute of Health and Medical Research (Inserm), Centre for Research in Epidemiology and Population Health (CESP), France

${ }^{7}$ Paris-Sud University, France

${ }^{8}$ Institut Gustave Roussy (IGR), France

${ }^{9}$ French National Institute of Health and Medical

Research (Inserm), Centre Léon Bérard, France

${ }^{10}$ Department of Chemical Contaminants in Food,

University of Paris-Est, France

${ }^{11}$ Ministry of Agriculture, France

*Corresponding author: Celia María Pereda, Head of Tumor Marker Lab, National Institute of Oncology and Radiobiology, Havana, Cuba

Received: October 10, 2018; Accepted: November 15, 2018; Published: November 22, 2018

\section{Keywords}

Case-control study; Differentiated thyroid cancer; Risk factors Genetic susceptibility; ATM; FOXE1; NKX2-1; Polymorphism; Recreational physical activity; Dietary iodine intake

\section{Background}

According to statistics from Globocán in 2008, thyroid cancer constituted $1 \%$ of all malignant diseases diagnosed in the world. Republic of Korea, New Caledonia and French Polynesia were the countries that reported the highest incidence and mortality, while Cuba and Martinique were the places with the highest incidence of this disease in the Caribbean Sea. Cuba is a multiethnic nation with people of African and Spanish descent. The registered incidence of Differentiated Thyroid Cancer (DTC) (follicular and papillary) in Cuba is low 4.1 per 100000 in females and 1.0 per 100000 in males, with 500 annual cases reported by the National Registry of Cancer (RNC). The disease is more frequent in women, around 35 years of age. The aims of these studies were identifying a set of risk factors for thyroid cancer in the Cuban population, as well as determining DNA polymorphisms related to the risk of developing the disease and its interaction with environmental factors and lifestyles.

\section{Study Design}

A case-control study was carried out, whose sample consisted of 202 prevalent cases of thyroid cancer, which were diagnosed before 50 years of age between years 2003-2010 and 212 supposedly healthy population controls, both residents in Havana and its surroundings and matched by age and sex. The cases were selected from the RNC data and the pathological anatomy lists of the Institute of Oncology and Radiobiology (INOR) and the Endocrinology Institute, both in Havana, Cuba, and the community controls of the primary care centers. The history of exposure of cases and controls was collected through structured interview face to face. The cases were interviewed at the hospital, by appointment of their attending physician and the controls were interviewed in the consultation of their family doctor and / or work center. Subjects who agreed to participate in the study through informed and signed consent, were asked for information on anthropomorphic characteristics, reproductive history, personal pathological history, in particular thyroid disease, family history of thyroid disease and cancer, occupational exposure, exposure to radiation ionizing agents, environmental factors, diet and lifestyles, as well as providing a saliva sample in order to dose the iodine and carry out genetic polymorphism studies. The study was supported by the Unit 605 and 754 of INSERM, in Paris, France.

\section{Results}

The most relevant results obtained showed that the risk of suffering from DTC is lower in populations of African origin increasing with parity and body surface area and was higher in peasants or people with some agricultural occupation, than in other populations that develop other types of activities [1]. The presence of artisanal wells as the main source of water consumption was significantly associated with an increase in the DTC, which could be due to a high concentration of nitrates in the water with respect to the sewerage network or the large-scale presence of metals or other elements [1]. In women, menopausal status and irregular cycles were associated with an increased risk of this disease [1], a higher risk was also observed in the case of individuals with benign thyroid disease [1], HR positive factor, as well as the risk was lower in habitual smokers than in nonsmokers [1]. Long-term recreational physical activity, practiced since childhood, may reduce the DTC risk [2].

For each genotyped polymorphism rs944289 near NKX2-1 and three polymorphisms near or within FOXE1, namely rs965513 on $9 q 22.33$, rs1867277 in the promoter region of the gene and the polyalanine tract expansion polymorphism rs71369530, as well as the coding SNP D1853N (rs1801516) in ATM the frequencies of alleles and genotypes were calculated, and the Hardy-Weinberg Equilibrium
Annals Thyroid Res - Volume 4 Issue 3 - 2018

Submit your Manuscript | www.austinpublishinggroup.com

Pereda et al. (C) All rights are reserved
Citation: Pereda CM, Lence-Anta JJ, María Ortíz R, Turcios S, Lesueur F, Xhaard C, et al. Risk Factors for Differentiated Thyroid Cancer. A Case-Control Study in Cuban Population. Annals Thyroid Res. 2018; 4(3): 164-165 
(HWE) was tested in the studied samples [3]. It has been observed that DTC risk was inversely associated with the fish intake and was positively associated with the number of copies in the minor allele (A) of rs965513 among people who consumed less iodine than the medium [4].

The five polymorphisms were in HWE among the control subjects analyzed. A systematic investigation of potential interactions between the five polymorphisms and the body surface area, body mass index, height, ethnicity and parity for women revealed a significant interaction $(p=0.03)$ between the SNP that codes for ATM and the number of pregnancies. Women with two or more pregnancies had an increase of 3.5 times the risk of having DTC if they transported the A allele [3]. It was an interesting fact the increased risk of DTC related to an increase in the number of pregnancies, also observed in the natives of French Polynesia where the average number of children is very high, around four children per woman in the controls [3]. These observations allow elucidating the biological role of ATM and possibly other DNA repair genes in the development of hormonerelated cancers, such as estrogen.

\section{Conclusion}

The risk factors analyzed play a preponderant role in the etiology of differentiated thyroid cancer and will allow to deepen in the early diagnosis of this disease as well as improve the treatment with more personalized and efficient strategies.

\section{References}

1. Juan J Lence-Anta, Constance Xhaard, Rosa M Ortiz, Haoiinda Kassim, Celia M Pereda, Silvia Turcios, et al. Environmental, Lifestyle, and Anthropometric Risk Factors for Differentiated Thyroid Cancer in Cuba: A Case-Control Study. Eur Thyroid J. 2014; 3: 189-196.

2. Constance Xhaard, Juan J Lence-Anta, Yan Ren, Françoise Borson-Chazot, Geneviève Sassolas, et al. Recreational Physical Activity and Differentiated Thyroid Cancer Risk: A Pooled Analysis of Two Case-Control Studies. Eur Thyroid J. 2016; 5: 132-138.

3. Celia M Pereda, Fabienne Lesueur, Maroulio Pertesi, Nivonirina Robinot, Juan J Lence-Anta, Silvia Turcios, et al. Common variants at the 9q22.33, $14 q 13.3$ and ATM loci, and risk of differentiated thyroid cancer in the Cuban population. BMC Genetics. 2015; 16: 22.

4. Yan Ren, Juan J Lence-Anta, Celia M Pereda, Mae Chappe, Milagros Velasco, Idalmis Infante, et al. FOXE1 Polymorphism Interacts with Dietary lodine Intake in Differentiated Thyroid Cancer Risk in the Cuban Population. Thyroid. 2016; 26: 1752-1760.
Annals Thyroid Res - Volume 4 Issue 3 - 2018

Submit your Manuscript | www.austinpublishinggroup.com

Pereda et al. (C) All rights are reserved
Citation: Pereda CM, Lence-Anta JJ, María Ortíz R, Turcios S, Lesueur F, Xhaard C, et al. Risk Factors for Differentiated Thyroid Cancer. A Case-Control Study in Cuban Population. Annals Thyroid Res. 2018; 4(3): 164-165 